\title{
Bioinspired Drill for Planetary Sampling: Literature Survey, Conceptual Design, and Feasibility Study
}

\author{
Yang Gao, $\stackrel{*}{-}$ Alex Ellery, $\stackrel{ \pm}{a}$ and Martin N. Sweeting $\stackrel{ \pm}{ \pm}$ \\ University of Surrey, Guildford, GU2 7XH England, United Kingdom \\ and \\ Julian Vincent $\underline{\underline{s}}$ \\ University of Bath, Bath, BA2 7AY England, United Kingdom \\ DOI: $\underline{10.2514 / 1.23025}$
}

\begin{abstract}
Growing interest in planetary subsurface exploration has prompted an examination of advanced drilling technologies. One of the major limitations of sampling in low gravity environments (such as Mars, asteroids, etc.) using conventional rotary drills is the need for high axial force, which suffers from big overhead mass, buckling problems, and power hungriness. Though drills using percussive motion may operate in low mass and power, the drilling rate is generally slow. Drawing inspiration from nature for a lighter weight and energy efficient solution, we propose a novel drilling method based on the working mechanism of wood wasp ovipositors. The bioinspired drill requires no reactive external force by applying two-valve-reciprocating motion. The proposed biomimetic system indicates enhanced utility that is critical for space missions where premium is placed on mass, volume, and power. Biological systems are similarly constrained making biomimetic technology uniquely suited and advantageous as a model of miniaturized systems. As a result of the European Space Agency project on bionics and space system design, this paper presents a literature survey of planetary drilling, working principle of the bioinspired drilling mechanism, a conceptual design, and feasibility study of the first prototype within a space system envelope.
\end{abstract}

$\begin{aligned} P & \text { Nom } \\ P & =\text { input power } \\ v_{d}= & \text { material removal rate } \\ \varepsilon & =\text { drilling speed }\end{aligned}$

\section{Introduction}

$\mathbf{I}^{\mathrm{T}}$ T IS widely acknowledged that the next significant challenge in planetary exploration is the ability to drill deep into the surface of solar system bodies. It is to obtain scientific data that can only be revealed below the surface. Examples include astrobiological research to search for biomarkers about 2-3 $\mathrm{m}$ beneath the surface layer due to ultraviolet flux exposure of most solar bodies (such as Mars [1]). And major studies at the lunar south pole region aim to search for water ice that is likely to exist under 1-2 $\mathrm{m}$ depth. The autonomous drilling system is therefore a crucial onboard instrument that can enable surface penetration, autonomous sample acquisition, and preparation for either in situ experiments or sample return procedures. The European Space Agency's (ESA) ExoMars and ESA/NASA's Mars Sample Return missions scheduled for 2011 and 2016 will both require a few meters drilling capability, and a great amount of work has to be performed in this area.

Conventional planetary drills can be classified into two categories, namely, rotary and percussive. The major limitation of using rotary drills in low gravity environment is the need for high axial force, which results in high overhead mass (e.g., use extensive land support

Presented at the IEEE Aerospace Conference 2006, Big Sky, MT, USA, 4 11 March 2006; received 6 February 2006; revision received 30 July 2006; accepted for publication 26 August 2006. Copyright @ 2006 by Dr. Yang Gao. Published by the American Institute of Aeronautics and Astronautics, Inc., with permission. Copies of this paper may be made for personal or internal use, on condition that the copier pay the $\$ 10.00$ per-copy fee to the Copyright Clearance Center, Inc., 222 Rosewood Drive, Danvers, MA 01923; include the code 0022-4650/07 \$10.00 in correspondence with the CCC.

*Research Fellow, Surrey Space Centre; yang.gao@surrey.ac.uk.

'Lecturer, Surrey Space Centre; a.ellery@ surrey.ac.uk.

†Professor, Surrey Space Centre; m.sweeting@ surrey.ac.uk.

§Professor, Centre for Biomimetic \& Natural Technologies; ensjfvv@ bath.ac.uk. structures). Rotary drilling also suffers from bit dulling/breaking/ jamming, power hungriness, and a long drill string for deep drilling. Percussive drills are more viable in terms of mass and power consumption, but they have a low penetration rate and difficulty in debris transport. This paper aims to present a novel drilling concept that provides a smaller, lighter, and more efficient energy solution to planetary subsurface exploration. Inspiration is drawn from the working mechanism of the wood wasp ovipositor drill. Such a biological system provides a good miniaturized model for a space system design that is similarly constrained by mass, volume, and power. This paper represents a continuation and extension of our previous work in $[2,3]$.

The rest of the paper is organized as follows. In Sec. II, a literature review on an existing drilling mechanism is presented. Advantages and disadvantages of conventional planetary drills are discussed that indicate the need for more advanced drilling technologies. Section III introduces the working principles of the bioinspired drilling mechanism and its significance. A conceptual design of the drill as a self-contained instrument is described in Sec. IV. Section $\underline{\mathrm{V}}$ provides a feasibility study of the proposed drilling mechanism based on the lab experiments. Discussions on an empirical drilling model and comparisons based on the test results are also included. Section VI concludes the paper and outlines future directions.

\section{Literature Survey on Planetary Drilling}

Despite conventional drilling such as rotary and percussive, there are a few ad hoc drilling techniques:

1) Shaped charges with metal liners eject a jet of molten metal to create a bore hole: this method eliminates contextual data and physically/chemically corrupts the environment.

2) Nontraditional drilling using power sources of laser, electron beam, or microwave, etc.: this method requires high power that is a scarce resource in outer space.

3) Melting tips drilling: this method requires high powers and corrupts the environment by forming a glass casing. This type of drilling is eminently suitable for penetrating into ice such as the comet surfaces, Martian polar caps, or European ice shell.

Because of high demand in power and energy, the above-mentioned methods are excluded from the main stream of planetary drilling. Based on the type of force applied, conventional planetary 
Table 1 Referenced planetary drills

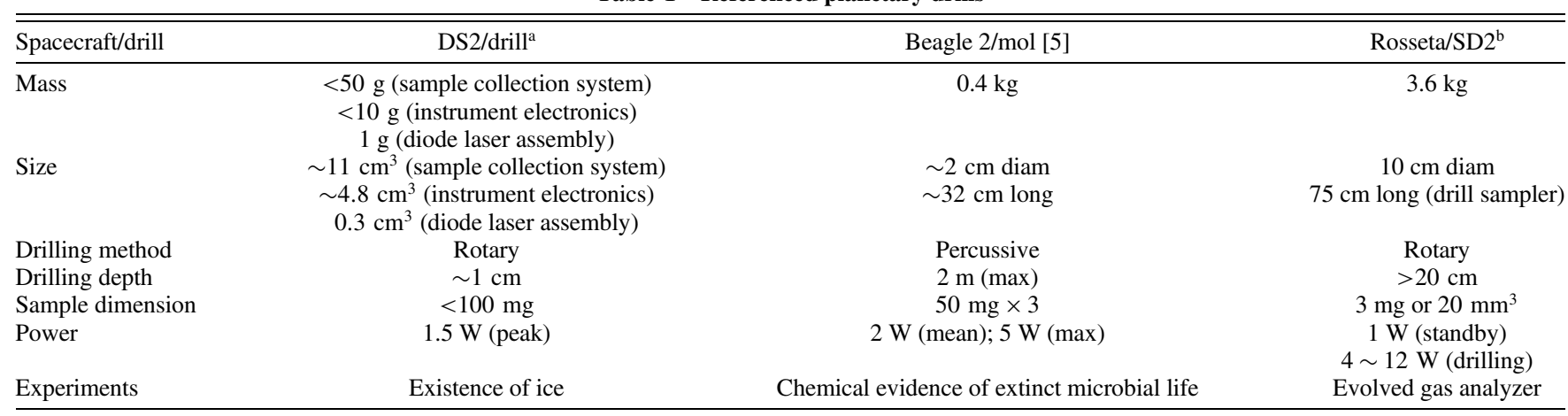

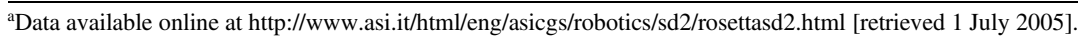

${ }^{\text {b}}$ Data available online at http://nmp.jpl.nasa.gov/ds2/tech/sample.html [retrieved 1 July 2005].

drills can be classified into two categories, namely, rotary and percussive.

Rotary drilling is the most common terrestrial approach to subsurface penetration. It is an extremely versatile method capable of penetrating cohesive and noncohesive soils and rock. It requires two motors (or a linked gearing single motor) to provide rotary action and vertical thrust. The major limitation of using rotary drills in low gravity environment (such as Mars, asteroids, etc.) is the need for high axial force, which results in high overhead mass (e.g., using extensive land support structures). Rotary drilling also suffers from bit dulling/breaking/jamming and power hungriness. The ESA Rosetta Lander uses a rotary coring tool (i.e., SD2) based on a helical auger to extract samples from $\sim 25 \mathrm{~cm}$ depth of a comet. $\mathbb{I}$ The rotary drill in the NASA Deep Space 2 microprobe operating at $10 \mathrm{rpm}$ was to drill up to $1 \mathrm{~cm}$ to extract $100 \mathrm{mg}$ soil from Mars.**The cancelled Champollion DS4 lander was designed to reach $10 \mathrm{~m}$ depth and required the automated construction of the drill string from multiple segments. The MicroRosa payload cab employs a similar approach to the autonomous construction of multiple drill segments into a growing drill string for a depth of $2 \mathrm{~m}$; it requires three separate motors. It suffers from the need to autonomously assemble the drill string beyond penetration depths of $1 \mathrm{~m}$. The combination of the need for autonomous drill string assembly and the problem of coping with dust offer a potentially hazardous situation for rotating parts that suggests that rotary drilling to high depths is an unreliable option. The honeybee robotics inchworm deep drilling system (IDDS) is an advanced design for penetrating depths $1-10 \mathrm{~km}$. It is composed of fore and aft sections which use a rotating drill bit at each end and braking shoes to provide reaction. The IDDS comprises two symmetrical segments each with a rotating drill bit at each end. A set of three braking shoes is mounted onto each segment to anchor to the walls of the bore hole as the opposing segment pushes downward. An extendible linkage powered by a linear actuator connected the two segments. Rotating helical flights on each segment pushed all cuttings to the rear of the vehicle. It was fully reversible capable of drilling downward and returning to the surface by virtue of its symmetric design. IDDS was $1 \mathrm{~m}$ in length by $10-15 \mathrm{~cm}$ in diameter with initial deployment via a launch tube. It was self-contained carrying its own power in the form of a radioisotope thermoelectric generator system to enable it to reach a $1-10 \mathrm{~km}$ depth. It may incorporate a coring sleeve and/or gas chromatography-mass spectrometry (GCMS) analyzer. This type of device would require a significant power rating to drive three braking shoes, the linear actuator, and rotating drill bit at any one time. Furthermore, a GCMS package would impose an even higher power requirement and mass overhead. The high power requirement precludes miniaturization of such a vehicle.

\footnotetext{
IData available online at http://www.asi.it/html/eng/asicgs/robotics/sd2/ rosettasd2.html [retrieved 1 July 2005].

**Data available online at http://nmp.jpl.nasa.gov/ds2/tech/sample.html [retrieved 1 July 2005].
}

Percussive drills are most viable in terms of power consumption, but they have a low penetration rate and difficulty in cuttings transport. Percussive drilling does not require drill fluid and uses short length drill strings. Drilling mud should not be used as they can potentially destroy the integrity of the bore hole environment. Examples include the ESA Beagle2 Mole, the Jet Propulsion Laboratory ultrasonic/sonic drilling/coring device (USDC), NASA Mars sub-surface explorer (SSX), etc. The USDC is based on a piezoelectric ceramic driven ultrasonic horn. It can drill through granite without blunting and it has a low mass $(0.5 \mathrm{~kg})$ and a low power requirement $(5 \mathrm{~W})$ [4]. However, it has a relatively low rate of penetration $\left(\sim 10^{-4} \mathrm{~m} / \mathrm{s}\right)$ and a small penetration depth. The use of detachable, self-propelled moles such as the Beagle2 Mole eliminates the need for long drill strings. Moles can penetrate into compacted regolith, though rock penetration is not possible. The Beagle2 Mole has a mass of $0.4 \mathrm{~kg}$ and a power requirement of 2 $5 \mathrm{~W}$. An electric motor restrains a percussive sliding hammer against a spring that is released once every $5 \mathrm{~s}$ [5]. It draws power and data from a tether to the mounting vehicle minimizing its mass. It has a relatively low penetration rate with a capability of $1 \mathrm{~cm} / \mathrm{min}$ in sand or $1 \mathrm{~mm} / \mathrm{min}$ in hardened regolith to a maximum depth of $5 \mathrm{~m}$. NASA has developed a variant of the Beagle 2 Mole, the $5 \mathrm{~kg} \mathrm{SSX,}$ which uses a spinning hammer on a screw thread. It requires 30 $50 \mathrm{~W}$ to penetrate at $5 \mathrm{~m}$ /day in hardened regolith. The SSX, rated to depths of $200 \mathrm{~m}$, is a mole that uses liquid carbon dioxide compressed from the Martian atmosphere and pumped from the surface through a thin tube to act as drilling mud. There is the possibility of using liquid Xe as drilling mud and/or epoxy fluids to extrude a solidifying hole casing. The use of fluids, however, introduces potential difficulties, as they require complex fluid handling capabilities such as pumps, valves, and hydraulics.

Table 1 provides properties of three planetary drills in three past and current space missions. They provide the baseline reference to the bioinspired drill design in this study.

\section{Bioinspired Drilling Mechanism}

\section{A. Biological Ovipositor Drill}

The wood wasp uses its ovipositor to drill holes into trees to lay its eggs. As shown in Fig. 1, the wood wasp ovipositor is about $0.26 \mathrm{~mm}$ in diameter, $10 \mathrm{~mm}$ in length, and in cross section can be split into two significant halves: one side is the cutting teeth and the other is the pockets for the sawdust to be carried away from the hole. Vincent and King [6] analyzed the working mechanism of the wood wasp ovipositor. The wasp first stabs the surface of the wood to stabilize the ovipositor. The initial cut is done by the small proximally facing teeth at the base of the ovipositor, which breaks the cell wall in tension. The rate of drilling remains low until the ovipositor is well supported in the narrow hole. Once this is achieved the push teeth can be used to cut the wood in compression without the fear of buckling. The push teeth are arranged in a staggered pattern to even out the forces required in cutting. The sawdust from the cutting teeth is 

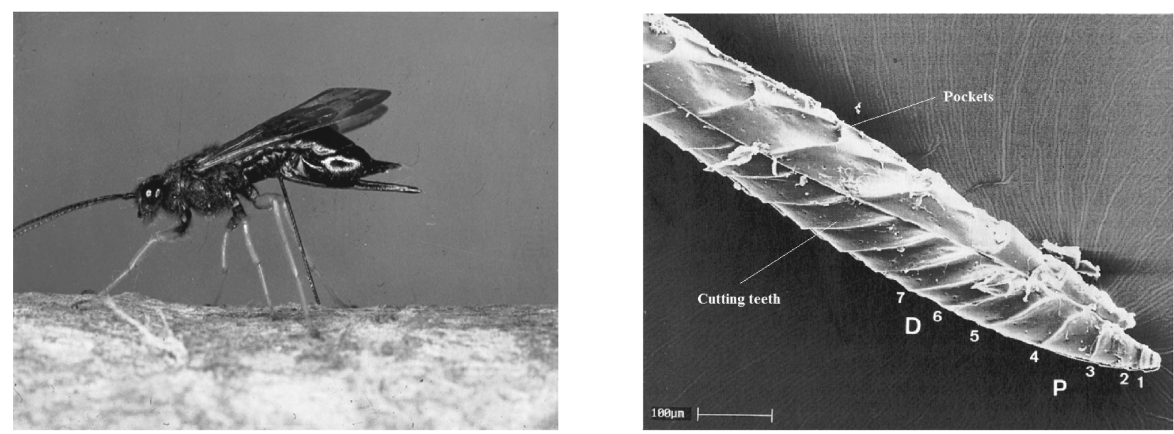

Fig. 1 Sirex wood wasp (left) and wood wasp ovipositor [ $[\underline{6}$ (right).

deposited into the pockets that then carry it to the surface on the upstroke. Two sides repeat this process in a reciprocating motion. The wasp ovipositor drills at a rate of around $1 \mathrm{~mm} / \mathrm{min}$ in the initial stage and $1.5 \mathrm{~mm} / \mathrm{min}$ in the later stages.

\section{B. Two-Valve-Reciprocating Drilling}

The ovipositor drill uses two-valve reciprocating rather than rotatory or percussive motion. The drill is composed of two valves that can slide against each other longitudinally as depicted in Fig. 2. The reciprocating drill has backward-pointing teeth that present little resistance to being moved downward but engage with the surrounding substrate to resist being moved in the opposite direction. Once the teeth are engaged, the tensile force that can be resisted, tending to pull the drill out of the substrate, allows the generation of an equal and opposite force in the other valve tending to push it further into the substrate. The drilling force is generated between the two valves and there is no net external force required. The limit to the drilling ability is the balance between the force required to pass through the rock, the degree of purchase that the teeth can obtain on the substrate, and the bending strength of the teeth when they are engaged with the substrate. Another intriguing aspect of the twovalve-reciprocating mechanism is the effect to the drilling debris. Because the adjacent valves are moving in opposite directions, the debris is moved up the hole rather than deeper into it. Given the working principal of the biological ovipositor drill described in Sec. III.A, it is worth noting that this novel drilling mechanism requires initial engagement of the cutting teeth and works for cohesive media (in opposite to loose media) to allow sufficient gripping of the cutting teeth.

As aforementioned, the major limitation of using the conventional rotary drills (e.g., Rosetta/SD2) in low gravity environments is the need for high axial force, which results in big overhead mass. The rotary drilling also suffers from power hungriness and long drill strings for deep penetration. Though percussive drills (e.g., Beagle 2/Mole, USDC) may offer low power consumption, their drilling rate is generally slow. A bioinspired drill based on two-valve reciprocating could provide a more compact and energy efficient solution (refer to Sec. V.C). The bioinspired drilling mechanism indicates some enhanced utility that may be incorporated into engineered systems inspired from biological systems. Such enhanced utility is critical for space missions where premium is placed on mass, volume, and power. Biological systems are similarly constrained making biomimetic technology uniquely suited as a model of miniaturized systems.

\section{Conceptual Designs}

\section{A. Overall Design}

The objective of this study is to design the wood wasp drill as a self-contained instrument that can be deployed from any machinery or platform. To represent the advancement in terms of mass, volume, and power, the following design requirements are applied: 1) size: 5 (max diam $) \times 7.5$ (max length) $\mathrm{cm} ; 2$ ) mass: $0.5 \mathrm{~kg}$; 3) power: $3 \mathrm{~W}$; 4) drilling depth: $\sim 2 \mathrm{~m}$.

Figure 3 illustrates the preliminary design of the drill. Extra volume budget has been added to ensure sufficient space for all the elements.

\section{B. Drill Bit Design}

The drill bit is designed in a way to mimic the cutting teeth of the ovipositor drill. As shown in Fig. 4 the drill bit is constructed in half cones (increasing in diameter) and the edges of the cones are used for the gripping and cutting action. The sharp pins or shims can be attached on the edge to increase gripping ability.

\section{Drill Bit Deployment}

Drill bits are attached to spring-loaded metal strips, which are reeled into a housing. The design of drill bit deployment is similar to a tape measure design, whereby the metal strip is wound into a reel. Upon reciprocation of the slider bars, the metal strip slides out of the housing (shown in Fig. 5). The curved metal strip is free to slide against the slider bar. As the drill digs into the substrate, sample particles will move up to the sample collection chamber (explained in the next section) and a hole is created. Once the drill bits are fully deployed a solenoid is activated to push the clip onto the metal strip that presses onto the slider bar. This allows the slider bar to pull the metal strip back out of the hole.

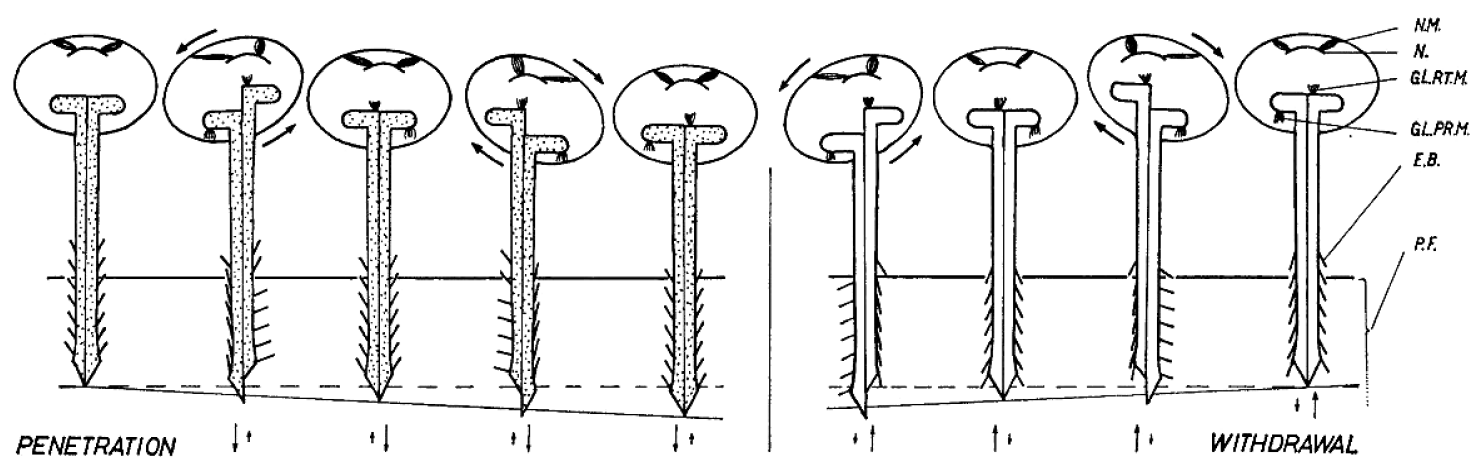

Fig. 2 Biological ovipositor drill. 


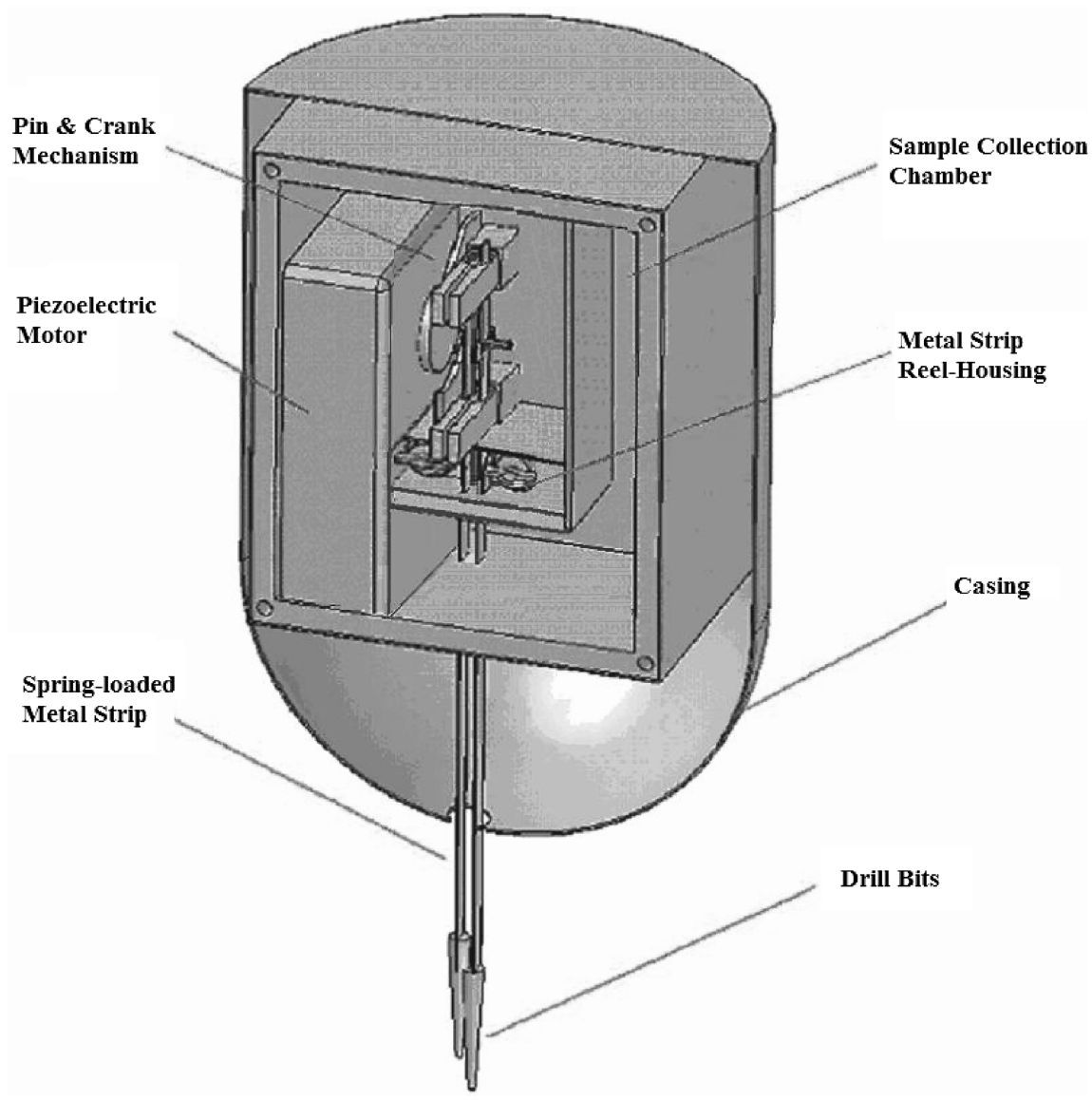

Fig. 3 Bioinspired drill and sampler system.

\section{Sample Extraction Mechanism}

A sample extraction method is designed based on the debris removal mechanism shown in Fig. $\underline{6}$. This mechanism works in twovalve-reciprocating motion the same as the drilling mechanism. When one side of the metal strip moves up, the other side moves down the same amount. Angled fibers are placed between the strips connected to the drill bit. Once particles are trapped inside the angled fibers between the metal strips, the fiber at one side lifts the particle and transports it to the opposite side. Consequently the particles can be collected between the metal strips and transported to the collection chamber and a hole is created. The bristle design may encounter problems of fragility and buckling under consecutive movement. However, slow planetary drilling speed and little overhead torque in the case help to reduce the risk of buckling. Robust layout and design of the bristles should help to prevent them from breaking.

\section{E. Drive Mechanism}

As shown in Fig. 3 , a cam mechanism is used to drive the drill. The pin-crank mechanism is versatile and able to obtain almost any arbitrary specified motion. It also offers the simplest and most compact way to transform motions.
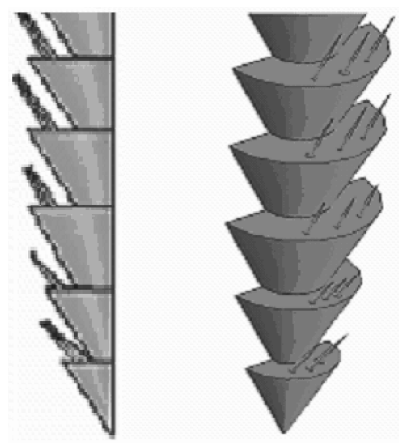

Fig. 4 2-D and 3-D views of the designed drill bit.

\section{F. Actuation Method}

To meet a low budget design in terms of size, weight, and power, the choice of actuation source is a piezoelectric actuator (a design baseline is suggested at PI Ceramic []]). Advantages of using the piezoelectric actuator include the following []]:

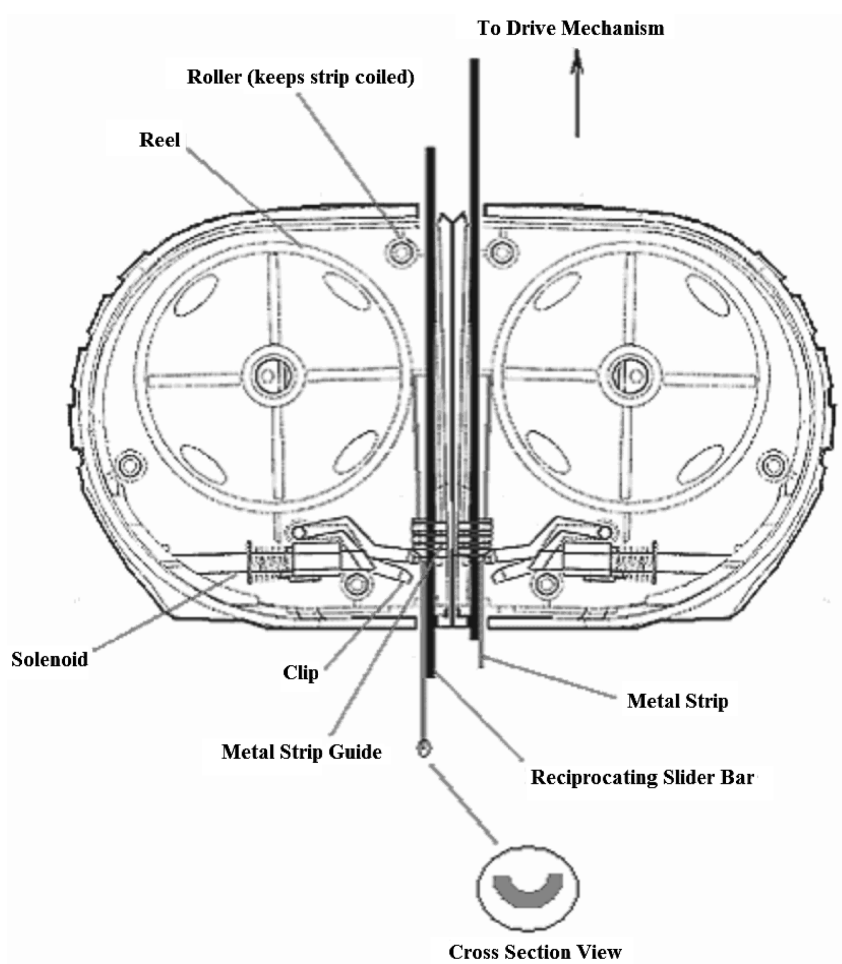

Fig. 5 Metal strip reel housing []]. 
1) high force generation and unlimited resolution: it can generate forces of several $10,000 \mathrm{~N}$ over a range of more than $100 \mu \mathrm{m}$ with subnanometer resolution;

2) rapid response: it can obtain microsecond time constants and acceleration rates of more than $10,000 \mathrm{~g}$;

3) no magnetic field: it is especially well suited for applications where magnetic fields cannot be tolerated as for space applications;

4) low power consumption: it directly converts electrical energy into motion, absorbing electrical energy during movement only. Static operation, even holding heavy loads, does not consume energy;

5) no wear and tear: it has neither gears nor rotating shafts and its displacement is based on solid-state phenomena and exhibits no wear and tear.

\section{Feasibility Studies}

\section{A. Lab-Based Experiments}

To verify the feasibility of the proposed drilling mechanism, a simplified drill prototype was built based on the design in Fig. $\underline{3}$, containing mainly the drill bit, drive mechanism, and actuator. The drill bit is $18 \mathrm{~mm}$ in diameter and made of steel. It was tested on three different substrates: condensed chalk, lime mortar, and none-fired
Table 2 Physical properties of a tested work piece

\begin{tabular}{lcc}
\hline \hline Work piece & Density $\left(\mathrm{kg} / \mathrm{m}^{3}\right)$ & Compressive strength $\varepsilon, \mathrm{MPa}$ \\
\hline Condensed chalk & 1500 & 0.65 \\
Lime mortar & 1560 & 0.95 \\
None-fired clay & 1769 & 4.8 \\
\hline \hline
\end{tabular}

clay (see Table 2 for their physical properties). For each test, a range of input power from 0 to $10 \mathrm{~W}$ was applied to the drill (nine sampling points were taken). Time was recorded using a stopwatch for drilling two holes of 0.025-m and 0.05-m deep, where predrilled holes were formed to allow initial gripping.

Figure 7 records the time for drilling into three substrates at two different depths. Harder material like clay (dark lines) takes a longer time to drill into than softer materials such as mortar (mid-dark lines) and chalk (white lines). The test results tend to show that the drilling speed increases as the drill digs deeper. This could be due to the fact that as drilling deeper the substrate starts to form cracks and hence becomes easier to be chipped off. However, we take the worst case by linearizing the test data to approximate drilling speed at different input powers. Figure $\underline{8}$ plots the approximated relationship between drilling speed and input power for a different test substrate. Given a

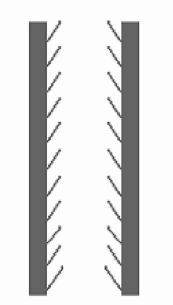

2 Plates with angled fibers

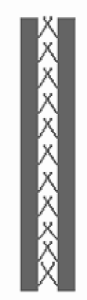

Placed together

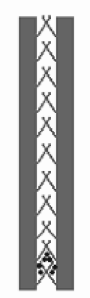

Particles at the bottom

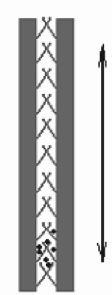

Moving one side up \& down moves the particls up, ejecting it to the side

Fig. 6 Debris removal mechanism [7].

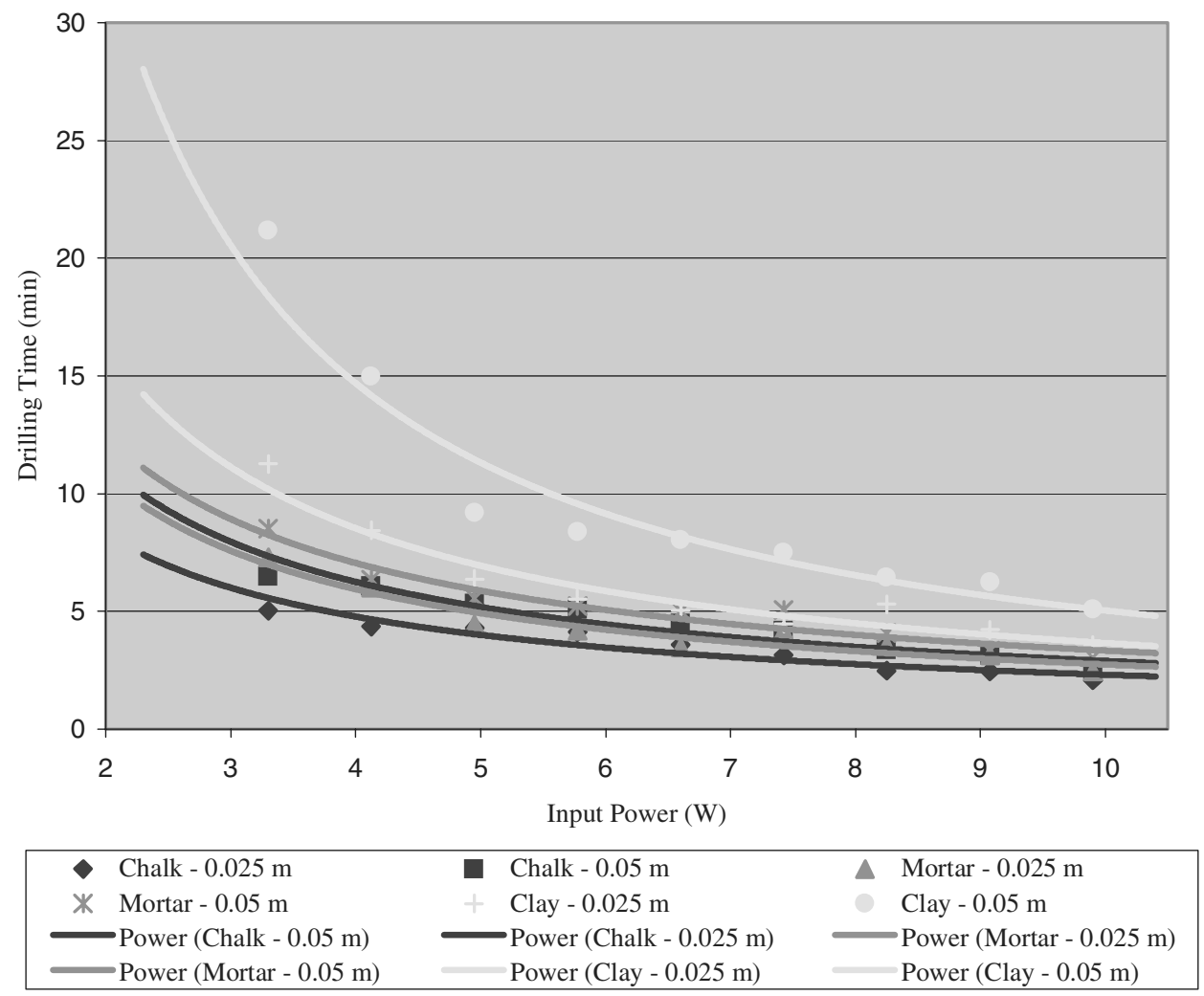

Fig. 7 Power versus drilling time of $0.025 \mathrm{~m} / 0.05 \mathrm{~m}$ depth. 
different input power budget, the drilling speed can be approximated for three work pieces. Drilling speed with respect to the work piece compressive strength can therefore be predicted for certain input power.

Figure $\underline{9}$ shows the results for input powers of 3,6 , and $9 \mathrm{~W}$.

\section{B. Empirical Drilling Model}

At this stage, the theoretical model of the novel bioinspired drilling is yet to be developed. Based on the experimental results shown in Figs. $\underline{8}$ and $\underline{9}$, an empirical model can be preliminarily formed to calculate the drilling speed, $v_{d}$, as follows:

$$
v_{d} \propto k \cdot P \cdot \frac{1}{\sqrt{\varepsilon}}
$$

where $v_{d}$ is direct proportional to a positive coefficient $k$, input power $P$, and inverse proportional to the square root of substrate compressive strength $\varepsilon$. The $k$ can be functions of relevant properties such as the work piece density, the drill bit geometry, and hardness, etc.

\section{Comparison Study}

The ratio of the input power over the material removal rate $(Q)$ provides a measure of energy efficiency taking into account that of

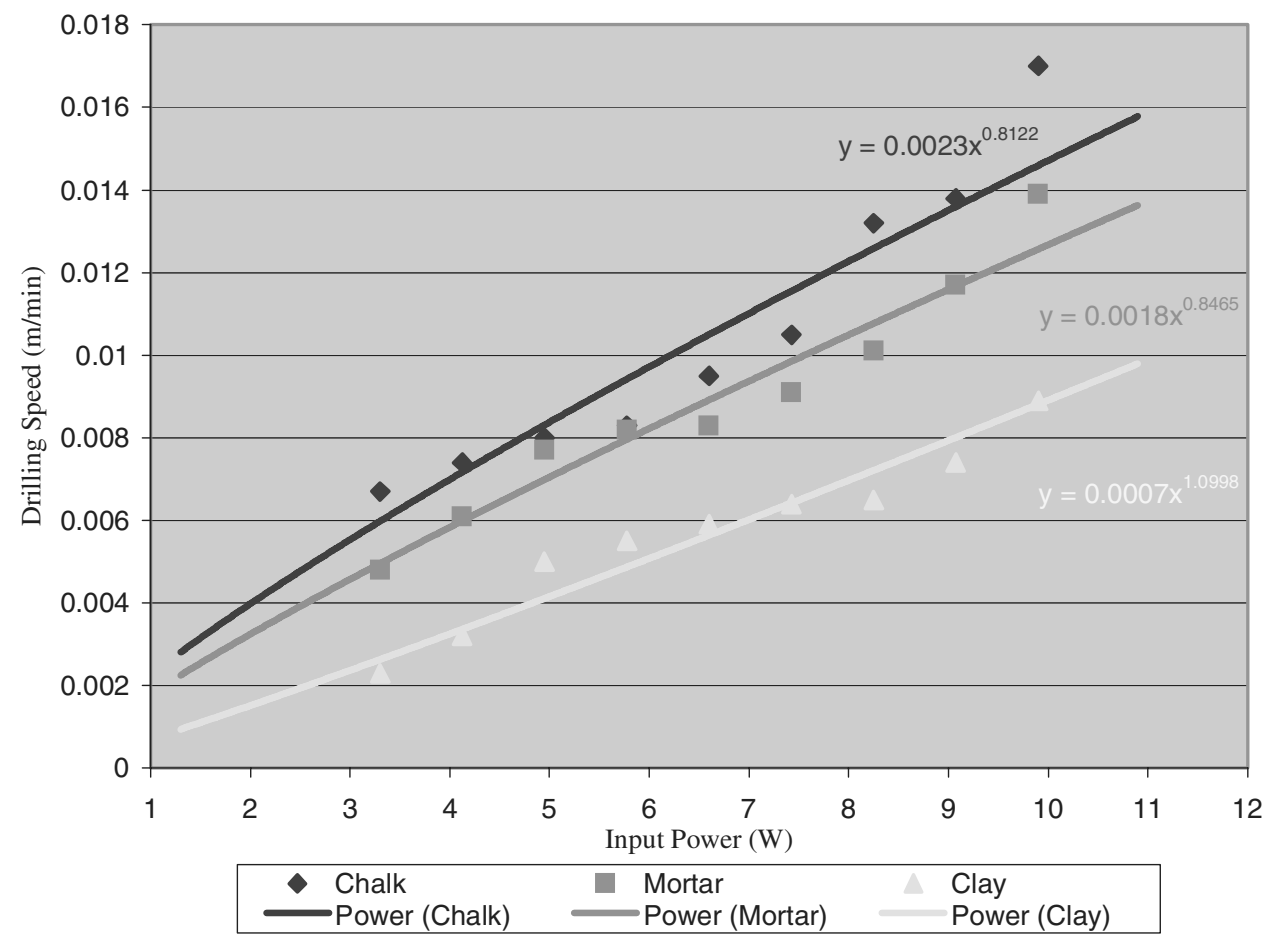

Fig. 8 Approximated drilling speed versus input power.

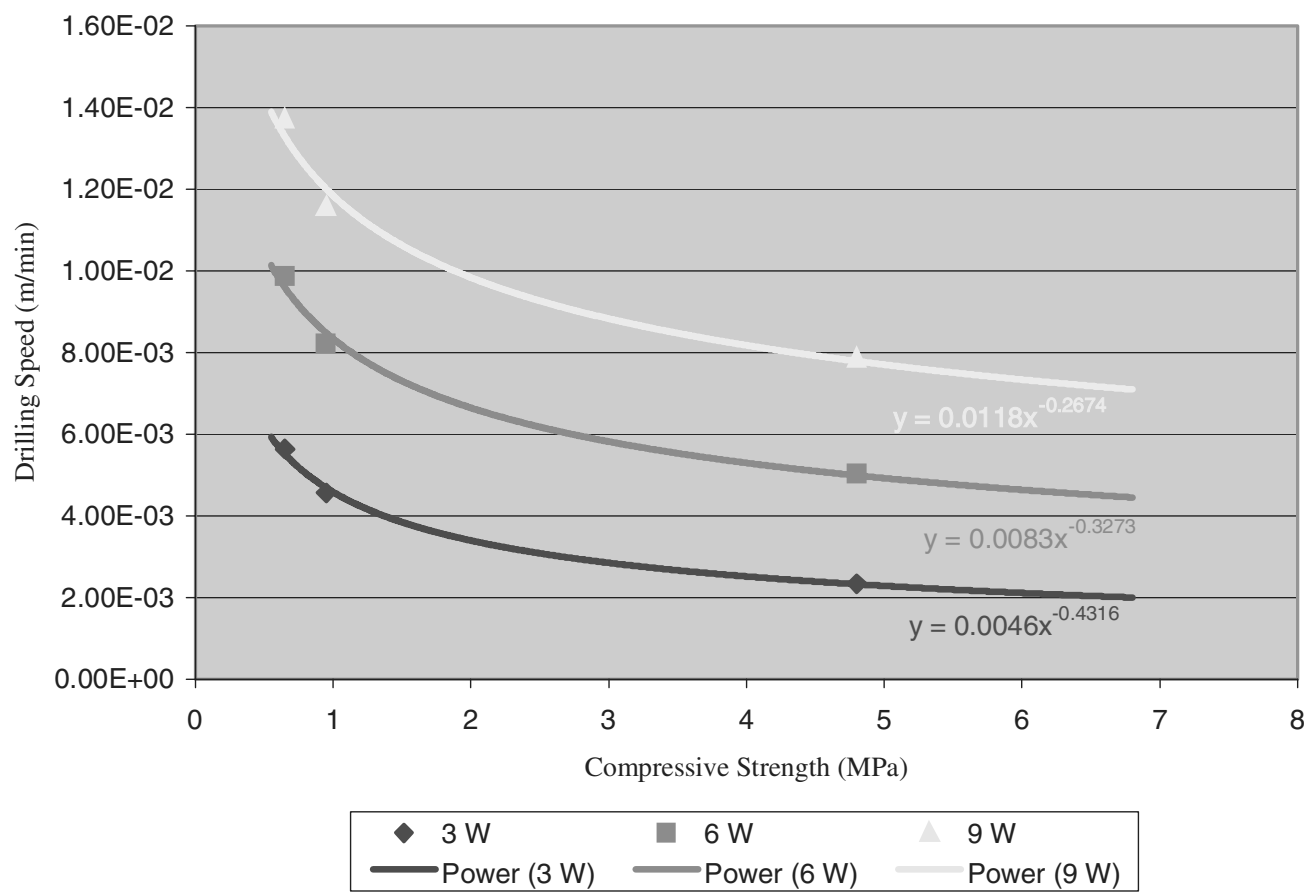

Fig. 9 Predicted drilling speed versus compressive strength at input power of 3, 6, and $9 \mathrm{~W}$. 
Table 3 Comparison of three drills

\begin{tabular}{|c|c|c|c|}
\hline & Bioinspired drill & Beagle $2 / \mathrm{mol}$ [5] & USDC [ [4] \\
\hline Drill diameter, $\mathrm{m}$ & 0.018 & 0.02 & 0.003 \\
\hline$P, \mathrm{~W}$ & 3 & 5 (peak) & 5 \\
\hline$v_{d}, \mathrm{~m} / \mathrm{s}$ & $\begin{array}{c}\sim 10^{-4 \underline{a}} \\
\sim 3 \times 10^{-5} \underline{b}\end{array}$ & $\sim 2 \times 10^{-4} \underline{a}$ & $\sim 10^{-4} \underline{b}$ \\
\hline$Q, \mathrm{~m}^{3} / \mathrm{s}$ & $\begin{array}{c}\pi \times 0.009^{2} \times 10^{-4} \underline{a} \\
\pi \times 0.009^{2} \times 3 \times 10^{-5} \underline{b}\end{array}$ & $\pi \times 0.01^{2} \times 2 \times 10^{-4} \underline{a}$ & $\pi \times 0.0015^{2} \times 10^{-4} \underline{b}$ \\
\hline$P / Q, \mathrm{~J} / \mathrm{m}^{3}$ & $\begin{array}{l}11.7 \times 10^{7} \mathrm{a} \\
3.9 \times 10^{8} \underline{\mathrm{b}}\end{array}$ & $6.4 \times 10^{7} \mathrm{a}$ & $7.07 \times 10^{9} \underline{b}$ \\
\hline
\end{tabular}

${ }^{\mathrm{a} F o r}$ media of $\sim 1 \mathrm{MPa}$ compressive strength.

${ }^{b}$ For media of $\geq 10 \mathrm{MPa}$ compressive strength.

power consumption and drilling speed. A smaller value of the ratio implies more energy efficiency of the drill. Table $\underline{3}$ compares the bioinspired drill with two percussive drills. The proposed drill provides comparable performance especially for handling harder substrates. For conventional rotary drills with similar performance would require high axial force of $\sim 10^{2} \mathrm{~N}$.

\section{Conclusions}

This paper proposed a bioinspired drill concept for planetary sampling that can be used as an instrument for a generic space mission. The biomimetic drill represents a novel approach of twovalve-reciprocating drilling based on a working mechanism of wood wasp ovipositors. It also has technology transfer applications within the terrestrial environment, such as geological drilling, ice coring, inhole petroleum exploration, etc. This paper covered an extensive discussion on planetary drilling, including literature review, feasibility study, and conceptual design of the proposed drill. A labbased experiment showed the potential of improving the drill efficiency within the low mass, volume, and power budget.

As for future studies, we need to develop the optimal geometry and material of the drill bit, experiment on a variety of substrates and the sample extraction method, enhance the empirical drilling model, and eventually build a system prototype.

\section{Acknowledgments}

This work was supported by the European Space Agency (ESA) under Bionics and Space System Design Contract No. AO/1-4469/ 03/NL/Sfe.

\section{References}

[1] Ellery, A., Kolb, C., Lammer, H., Parnell, J., Edwards, H., Richter, L.,
Patel, M., Romstedt, J., Dickensheets, D., Steele, A., and Cockell, C., "Astrobiological Instrumentation for Mars-The Only Way Is Down," International Journal of Astrobiology, Vol. 1, No. 4, 2003, pp. 365380.

[2] Gao, Y., Ellery, A., Jaddou, M., Vincent, J., and Eckersley, S., “A Novel Penetration System for in situ Astrobiological Studies," International Journal of Advanced Robotic Systems, Vol. 2, No. 4, 2005, pp. 281286.

[3] Gao, Y., Ellery, A., Jaddou, M., Vincent, J., and Eckersley, S., "A Planetary Micro-Penetrator Concept Study with a Biomimetic Drill \& Sampler Subsystem," IEEE Transactions of Aerospace and Electronic Systems (to be published).

[4] Bar-Cohen, Y., Sherrit, S., Bao, X., and Chang, Z., "Ultrasonic/Sonic Sampler and Sensor Platform for in-situ Planetary Exploration," Proceedings of the IEEE International Conference on MEMS, NANO and Smart Systems, IEEE, Piscataway, NJ, 2003.

[5] Richter, L., Coste, P., Gromov, V. V., Kochan, H., Nadalini, R., Ng, T. C., Pinna, S., Richter, H.-E., and Yung, K. L., "Development and Testing of Subsurface Sampling Devices for the Beagle 2 Lander," Planetary and Space Science, Vol. 50, No. 2, 2002, pp. 903-913.

[6] Vincent, J. F. V., and King, M. J., "The Mechanism of Drilling by Wood Wasp Ovipositors,” Biomimetics, Vol. 3, No. 4, 1995, pp. 187-201.

[7] Zacny, K., Quayle, M., McFadden, M., Neugebauer, A., Huang, K., and Cooper, G., "A Novel Method for Cuttings Removal from Holes During Percussive Drilling on Mars," Proceedings of Revolutionary Aerospace Systems Concepts-Academic Linkage (RASC-AL), 2002.

[8] Tutorial on Piezoelectric Actuators, PI Ceramic, Germany, http:// www.piceramic.de/pdf/PIC_Tutorial.pdf [retrieved July 2005].

[9] Jaddou, M., "Autonomous Biomimetic Drill Based on a Sirex Wood Wasp," Project Report, University of Bath, 2005. 